\section{Inheritance of Resistance to Cucurbit Powdery Mildew in Bitter Gourd}

\author{
Narinder P.S. Dhillon ${ }^{2}$, Supannika Sanguansil ${ }^{1}$, Supornpun Srimat, \\ and Suwannee Laenoi \\ World Vegetable Center, East and Southeast Asia, Kasetsart University, \\ Kamphaeng Saen, Nakhon Pathom 73140, Thailand
}

Roland Schafleitner

Biotechnology, World Vegetable Center, P.O. Box 42, Shanhua, Tainan 74199, Taiwan

\section{Michel Pitrat}

INRA (French National Institute for Agricultural Research) GAFL (Genetics and Breeding of Fruit and Vegetables), Domaine Saint Maurice, CS 60094, 84143 Montfavet cedex, France

\section{James D. McCreight}

U.S. Department of Agriculture, Agricultural Research Service, U.S. Agricultural Research Service, 1636 E. Alisal Street, Salinas, CA 93905

Additional index words. Momordica charantia, Podosphaera xanthii, race-specific resistance, allelic and non-allelic resistance

\begin{abstract}
Cucurbit powdery mildew (CPM) caused by Podosphaera xanthii (Px) is an economically important disease of bitter gourd (BG; Momordica charantia) in Asia. Highlevel resistance to $\mathrm{CPM}$ is known in various $\mathrm{BG}$ accessions that have been used to develop BG breeding lines that originated in different countries. BG breeding lines THMC 113 (Belize), THMC 143 (India), THMC 153 (Thailand), THMC 167 (India), and THMC 170 (Taiwan) possess high-level resistance to BG Px race (BG-CPM), designated Mc-1 from a field at Kamphaeng Saen, Thailand, whereas THMC 144 (India) is susceptible. Our objective was to determine the inheritance of resistance to BG-CPM race Mc-1. To that end, THMC 144 (India) was crossed with the five resistant lines. The parents and their respective $F_{1}, F_{2}$, backcross progenies were evaluated for $B G-C P M$ disease severity in inoculated field and growth chamber tests. Resistance to BG-CPM race Mc-1 in the five resistant lines was controlled by at least two independent, recessive genes. Intercrosses of the BG-CPM-resistant lines revealed allelic resistances in four of the breeding lines: THMC 113, THMC 153, THMC 167, and THMC 170. Resistance in THMC 143 was clearly non-allelic for resistance to BG-CPM with the other four BG-CPM-resistant lines.
\end{abstract}

CPM, caused by $P x$, has become one of the most serious diseases of field and greenhouse cucurbits worldwide (Krístková et al., 2009; McGrath, 2017; Sitterly, 1978). It is a serious fungal disease of BG (Momordica

Received for publication 24 Jan. 2019. Accepted for publication 1 Apr. 2019.

Funding for this research was provided by the Federal Ministry for Economic Cooperation and Development, Germany (BMZ, Project no. 10000236), Japan Ministry of Agriculture, Forestry and Fisheries (Japan MAFF, Project no. 10000347), and long-term strategic donors to the World Vegetable Center: Republic of China (ROC), UK aid from the UK government, United States Agency for International Development (USAID), Australian Center for International Agricultural Research (ACIAR), Germany, Thailand, Philippines, Korea, and Japan.

${ }^{1}$ Current address: Chia Tai Company Limited, Khwang Samphanthawong, Khet Samphanthawong, Bangkok 10100, Thailand.

${ }^{2}$ Corresponding author. E-mail: narinder.dhillon@ worldveg.org. sustainable management of CPM can be achieved through genetic host plant resistance.

One hundred fifty BG accessions of the World Vegetable Center Genebank were screened for resistance to a local isolate of $P x$ at Kamphaeng Saen, Thailand. A single resistant plant was identified in each of five heterogeneous populations derived from five of the accessions that originated from India, Thailand, Taiwan, and Belize. Multiple cycles of inbreeding and selection led to the development of five $P x$-resistant inbred lines: THMC 113, THMC 143, THMC 153, THMC 167, and THMC 170. These lines were uniformly resistant to the local isolate of $P x$ in Kamphaeng Saen, Thailand, in field tests over three seasons (Dhillon et al., 2018). The objective of this study was to understand the mode of inheritance of resistance to CPM in the five inbred lines

\section{Materials and Methods}

Field trials and inoculations. The BG breeding lines used in this study included the BG-CPM-susceptible line THMC 144 and five BG-CPM-resistant lines: THMC 113, THMC 143, THMC 153, THMC 167, and THMC 170. The resistant lines were used as pollinators in crosses with THMC 144 to produce the $F_{1}$ generation for each inbred line, from which the respective $F_{2}$, and reciprocal backcrosses were produced. The resistant lines were intercrossed and their $F_{1}$ progenies tested to determine allelic relationships of their resistance genes.

BG-CPM incited by $P x$ is observed annually in the BG fields at the World Vegetable Center Research and Training Station, East and Southeast Asia, Kamphaeng Saen, Thailand, during November to January. The susceptible check variety THMC 144 exhibits $100 \%$ susceptibility when planted in the field in this period, and the five other lines are resistant, indicating that this strain belongs to race Mc-1 (Dhillon et al., 2018). Twenty plants of each parent and each $F_{1}$ generation, 100 plants of each backcross generation, and 200 plants of each $\mathrm{F}_{2}$ generation were evaluated for resistance to BGCPM (no replicates). Seeds were sown and plants transplanted 13 Nov. and 23 Nov. 2016, respectively. Plants were arranged in single rows on raised beds with a row spacing of $1.6-\mathrm{m}$ and $1-\mathrm{m}$ within-row spacing, and staked. BG-CPM-susceptible THMC 144 was transplanted on the boundary of the test field 2 weeks before establishment of the genetic study to increase the BG-CPM inoculum level. Additional spreader rows of THMC 144 were transplanted around the field at the time the genetic study was transplanted. Seedlings were inoculated (with inoculum collected from the leaves of BGCPM-susceptible THMC 144 plants) before transplanting at the three to four true leaf stage and at 20 days' posttransplanting. Each plant was inoculated to runoff, using a 1-L hand sprayer, with a spore suspension of $P x$ prepared as follows. Freshly prepared spores were washed from detached, heavily infected 
leaves with a spray of $100 \mathrm{~mL}$ of water and filtered through a double layer of cheesecloth and diluted to a concentration of $4 \times 10^{4}$ conidia/mL, as determined by a hemocytometer. Disease severity 30 days' postinoculation was rated on the first five true leaves of individual 50-day-old plants using a 0 to 5 visual rating scale, where $0=$ free from fungal infection; and $1=1 \%$ to $10 \%, 2=$ $11 \%$ to $25 \%, 3=26 \%$ to $50 \%, 4=51 \%$ to $75 \%$, and $5=\geq 75 \%$ leaf surface covered with BG-CPM. BG-CPM-susceptible THMC 144 was uniformly rated 5 at that time.

Growth chamber tests. THMC 144, THMC 113, THMC 143, THMC 153, and THMC 167 , and their respective $F_{1}, F_{2}$, and backcross generations to THMC 144 were included in this test; numbers of plants in the $\mathrm{F}_{2}$ populations ranged from 84 to 120 (Table 1). Seeds were sown and plants were raised until the second-leaf stage in a glasshouse, at which time they were inoculated as described previously, spraying until runoff with a spore suspension in water at a concentration of $5 \times 10^{4}$ conidia $/ \mathrm{mL}$. A singlespore CPM strain isolated from $M$. charantia grown in an open field in Kamphaeng Saen,
Thailand, was used as source of inoculum; it was identified as race Mc-1 (Dhillon et al., 2018). A single spore was taken under a binocular with an eye lash and deposited on a Lagenaria (bottle gourd) cotyledon maintained in axenic conditions. This operation was conducted twice. The single-spore isolate was then maintained and multiplied in vitro on Lagenaria cotyledons for long-term storage in liquid nitrogen or in a freezer at $-80{ }^{\circ} \mathrm{C}$. The inoculated plants were incubated after inoculation in a growth chamber (16-h day $26{ }^{\circ} \mathrm{C} / 8$-h night $20{ }^{\circ} \mathrm{C}$ ). Disease severity at 14 days postinoculation was rated on the second leaf using a 0 to 3 visual rating scale, where $0=$ no visible symptoms, $1=$ chlorotic local lesions with very light sporulation observed upon close examination, 2 = clear sporulation but not abundant, and $3=$ abundant sporulation corresponding to susceptible control.

Greenhouse test. Allelic relationships for resistance to BG-CPM race $\mathrm{Mc}-1$ were investigated in a single greenhouse test. The five BG-CPM-resistant lines were intercrossed in a half diallel. Their $\mathrm{F}_{1}$ progenies (10 plants of each progeny) were transplanted into pots $(10 \times 15 \mathrm{~cm})$ and inoculated at the 10-leaf stage, as described previously for field tests. Disease severity at 14 days postinoculation was rated using the 0 to 5 visual scale described for field test.

For both field and growth chamber tests, $\chi^{2}$ was used to test goodness-of-fit of observed to expected ratios using SAS-STAT statistical package (SAS Institute, Cary, NC).

\section{Results}

Inheritance study. THMC 113, THMC 143, THMC 153, THMC 167, and THMC 170 were uniformly resistant to infection, and, as expected, THMC 144 was uniformly observed highly susceptible with disease ratings (DR) of 5 and 3 in the field and growth chamber tests, respectively (Table 1). The five $F_{1}$ progenies from crosses of susceptible THMC 144 with the resistant lines also were uniformly rated 5 for disease severity in the field test. The $\mathrm{F}_{1}$ progenies with THMC 113, THMC 143, and THMC 167 were susceptible (ratings of 2 and 3 ) in the growth chamber with symptoms typical of CPM, whereas five plants of the $\mathrm{F}_{1}$ THMC

Table 1. Cucurbit powdery mildew disease reactions of five resistant and one susceptible (THMC 144) bitter gourd breeding lines and their respective $\mathrm{F}_{1}$, $\mathrm{F}_{2}$, backcross progenies from crosses of the susceptible THMC 144 with the five resistant lines in field ( $0-5$ rating scale) and growth chamber $(0-3$ rating scale) tests.

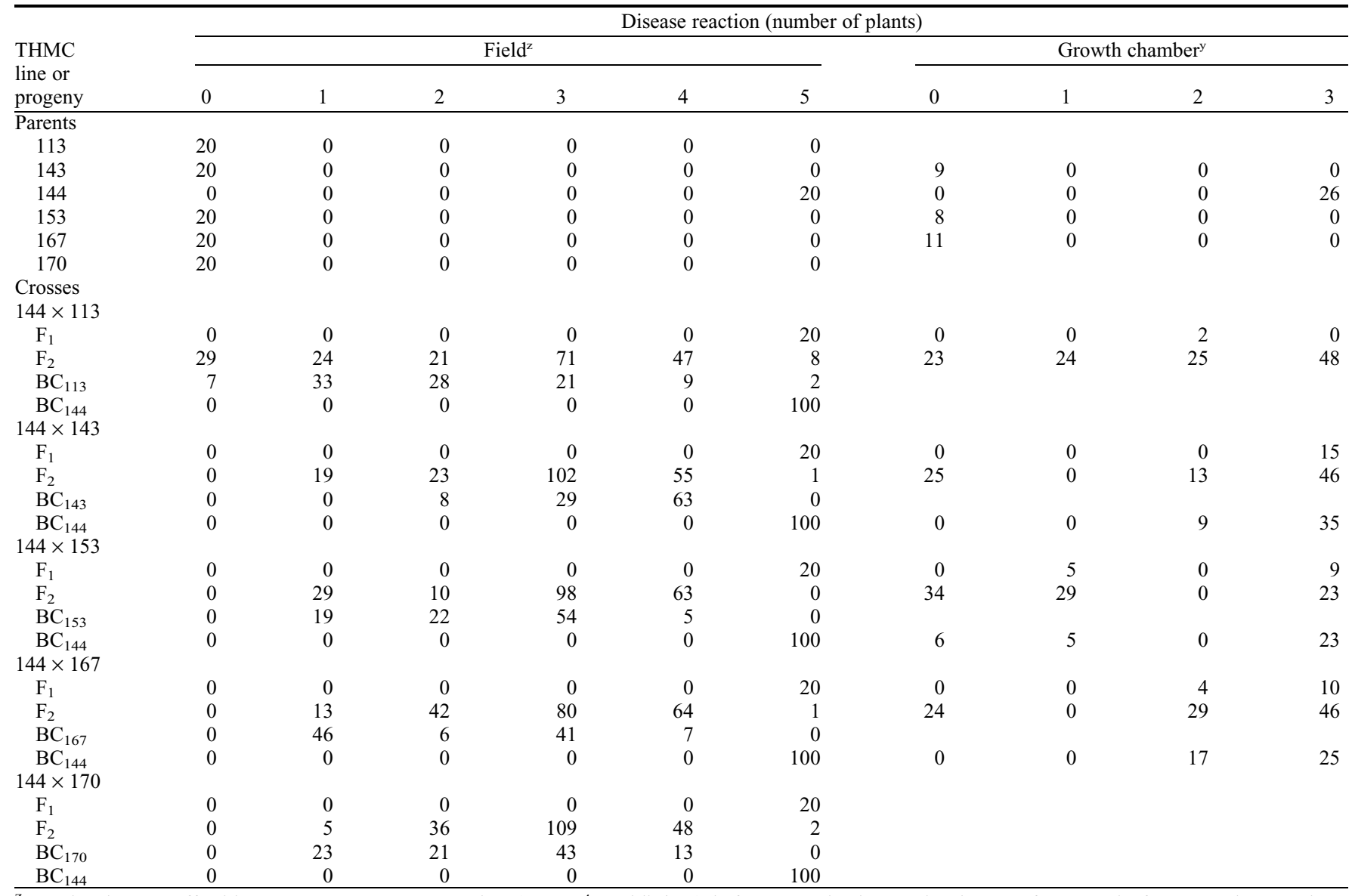

${ }^{\mathrm{z}}$ Inoculated to runoff with an aqueous spore suspension $\left(4 \times 10^{4}\right.$ conidia/mL) before transplanting at the three to four true leaf stage and at 20 days' posttransplanting. Disease severity rated on the leaves of individual 50 -day-old plants using a $0-5$ visual rating scale, where $0=$ no visible infection, $1=1 \%$ to $10 \%, 2=11 \%$ to $25 \%, 3=26 \%$ to $50 \%, 4=51 \%$ to $75 \%$, and $5=\geq 75 \%$ leaf surface covered with CPM.

${ }^{\mathrm{y}}$ Inoculated to runoff with an aqueous spore suspension $\left(5 \times 10^{4}\right.$ conidia/mL $)$ at the two-leaf stage. Disease severity rated at the second leaf stage using a $0-3$ visual rating scale, where $0=$ no visible symptoms, 1 = very light sporulation, 2 = clear sporulation but not abundant, and $3=$ abundant sporulation corresponding to susceptible control. 
$144 \times$ THMC 153 were rated 1 and nine plants were rated 3 (Table 1). These data clearly indicate recessive inheritance of this trait in the five resistant lines.

The $\mathrm{F}_{2}$ THMC $144 \times$ THMC 113 segregated in the field test in an acceptable fit to a 3 resistant $(\mathrm{DR}=0)$ : 13 susceptible $(\mathrm{DR}=1$ to 5) $\left(\chi^{2}=2.37, P=0.13\right)$, which suggests two recessive genes with epistasis (Table 1). This model was not confirmed by the backcross of the $\mathrm{F}_{1}$ to the resistant parent when considering the class $\mathrm{DR}=0$ as resistant and the $\mathrm{DR}=$ 1 to 5 classes as susceptible. When DR classes 0 and 1 are, however, combined, the segregations of the two generations support a single recessive gene model, where the $\mathrm{F}_{2}$ segregated 53 resistant: 147 susceptible $\left(\chi^{2}=\right.$ $0.24, P=0.63)$, and the backcross of the $\mathrm{F}_{1}$ to the resistant parent segregated 40 resistant: 60 susceptible $\left(\chi^{2}=4.0, P=0.046\right)$. The single recessive gene model was supported by growth chamber results (Table 1), where the $F_{2}$ THMC $144 \times$ THMC 113 segregated in an acceptable fit to a 1 resistant $(\mathrm{DR}=0): 3$ susceptible (DR $=1$ to 3$)\left(\chi^{2}=2.178, P=\right.$ $0.14)$. This single recessive model is, however, challenged by the conflict in classifying plants in the field test with as much as $10 \%$ infected foliage as resistant, and then applying a greater threshold in the growth chamber tests where plants with very light sporulation are classified susceptible.

In contrast to the THMC $144 \times$ THMC 113 cross, there were no resistant $(\mathrm{DR}=0)$ segregants in any of the other four $\mathrm{F}_{2}$ progenies in the field test, which suggests additional recessive, perhaps epistatic, loci for resistance to BG-CPM race Mc-1; combining DR classes 0 and 1 did not produce acceptable single or digenic segregations. Their respective backcross progenies to THMC 144 (susceptible) were highly susceptible. There were no resistant $(\mathrm{DR}=0)$ segregants in the respective backcrosses to the four resistant parents, although when DR classes 0 and 1 were combined, two (THMC 153 and THMC 170) segregated in acceptable fits to 1 resistant: 3 susceptible expected in a digenic model; $\chi^{2}$ values (and probabilities) were, respectively, $1.92(0.17)$ and $0.21(0.66)$.

In the growth chamber tests, $\approx 25 \%$ of the plants in $\mathrm{F}_{2}$ progenies with THMC 143 and THMC 167 were resistant; $\chi^{2}$ values (and probabilities) were, respectively, $1.016(0.31)$, and $0.03(0.86)$. Only two backcrosses $\left(\mathrm{F}_{1} \times\right.$ THMC 144) were included in the growth chamber tests; they were both susceptible. The growth chamber data suggest single recessive genes for resistance to $\mathrm{BG}-\mathrm{CPM}$ race Mc-1 in THMC 113, THMC 143, and THMC 167. In contrast, THMC 153 produced distinctive results in the growth chamber. Some individuals in the $F_{1}$ and $F_{2}$ generations exhibited very light symptoms with chlorotic lesions $(\mathrm{DR}=1)$. The $\mathrm{F}_{1}$ was not as susceptible as those with the other breeding lines, and the $F_{2}$ segregated a greater number of resistant (growth chamber $\mathrm{DR}=0)$ plants than acceptable in a single recessive gene model $\left(\chi^{2}=9.69, P=0.002\right)$. In the BC with THMC 144, six plants were observed without symptoms and five with chlorotic lesions. Resistance in accession THMC 153 seems to be controlled by gene(s) with intermediate (not fully recessive) resistance.

Allelic relationships. All offspring from crosses among four inbred lines THMC 113, THMC 153, THMC 167, and THMC 170 were resistant, which suggests that the same locus is involved in the resistance of these four BG inbred lines against BG-CPM race Mc-1 (Table 2). In contrast, the $\mathrm{F}_{1}$ progenies between THMC 143 and the four other resistant lines were fully susceptible, indicating a different major locus for resistance in this accession.

\section{Discussion}

BG is an important cash crop and its current seed market in Asia is worth $\approx 16$ million Euros (Dhillon et al., 2016). It is mainly cultivated by smallholder farmers in Asia, where CPM is major cucurbit production constraint in the field as well as glasshouse production systems (Lebeda et al., 2010); the adoption of CPM-resistant BG cultivars will enhance the profitability of the farmers while reducing numbers and frequency of chemical control and potential adverse environmental effects. The five BGCPM-resistant breeding lines used in this study have been observed resistant to many local isolates of $P x$ during multilocation testing in Thailand, Vietnam, Philippines,
Myanmar, China, India, and Bangladesh (Dhillon et al., 2018).

Race-specific resistance has been used to breed CPM-resistant cultivars of cucurbit species such as muskmelon, Cucumis melo L. (Dhillon et al., 2012), watermelon, Citrullis lanatus (Thunb.) Matsum. \& Nakai (Ben-Naim and Cohen, 2015), squash and pumpkin, Cucurbita sp. (Jahn et al., 2002). There are currently no available cultivars of $\mathrm{BG}$ resistant to $\mathrm{CPM}$.

CPM species $P x$ has a high evolutionary potential (McDonald and Linde, 2002) and is, therefore, likely to overcome such kind of race-specific resistance. This has been borne out in melon, for which the number of races has increased to such a large number that an international powdery race initiative was proposed based on a triple-septet set of melon cultivars, breeding lines, and accessions to objectively and systematically designate melon CPM races (Lebeda et al., 2016). The melon seed industry, working through the International Seed Federation and Center for Pathogen Strain Identification, University of California, Davis, initiated the development of a reduced set of melon CPM race differentials designed to identify the economically important races yet reveal presence of unique races (J.D. McCreight).

The discrepancy in reactions of the $F_{2}$ progenies between the field and growth chamber tests was likely due to several factors: 1) the use of a single-spore-derived strain in the growth chamber vs. an unknown mixture of strains in the field; 2) plant age, i.e., young plants in the growth chamber vs. older plants in the field; 3) more severe infection in the field due to multiple inoculum sources and cycles of multiplication of CPM over the 30-day period of disease development in the field tests vs. 14-day period of disease development following a single inoculation in the growth chamber test; and 4) differences in the disease reaction rating scales. The scale used for field evaluations is proportional to the surface of the leaf covered with powdery mildew, which resulted from several cycles of multiplication and infection by powdery mildew. The severity scale used for the growth chamber tests is proportional to the intensity of the sporulation because there is only one cycle of

Table 2. Allelic relationships between five bitter gourd lines carrying recessive genes for resistance against $P x$. Resistant lines were intercrossed; 10 plants of each $\mathrm{F}_{1}$ were evaluated for disease reaction to CPM; artificial inoculation test in a greenhouse.

\begin{tabular}{|c|c|c|c|c|c|c|}
\hline \multirow[b]{2}{*}{$\mathrm{F}_{1}$ progeny } & \multicolumn{6}{|c|}{ Disease reaction (number of plants) ${ }^{z}$} \\
\hline & 0 & 1 & 2 & 3 & 4 & 5 \\
\hline THMC $113 \times$ THMC 153 & 10 & & & & & \\
\hline THMC $113 \times$ THMC 170 & 10 & & & & & \\
\hline THMC $143 \times$ THMC 153 & & & & & & 10 \\
\hline THMC $143 \times$ THMC 167 & & & & & & 10 \\
\hline THMC $143 \times$ THMC 170 & & & & & & 10 \\
\hline THMC $167 \times$ THMC 170 & 10 & & & & & \\
\hline
\end{tabular}
covered with CPM. 
infection/multiplication, and thus the number of mildew colonies is proportional to the concentration of the inoculum. Nevertheless, the main conclusions are that resistance to BG-CPM in these five breeding lines is recessive and that at least two loci are involved.

Four BG-CPM races are known. This study was conducted with race $\mathrm{Mc}-1$, to which all five breeding lines are resistant (Dhillon et al., 2018). THMC 153 and THMC 167 were resistant to all four races (Mc-1, Mc-2, Mc-3, Mc-4) in that study, whereas THMC 113 and THMC 143 were susceptible to one race (Mc-3 and $\mathrm{Mc}-4$, respectively), and THMC 170 was susceptible to two races (Mc-2 and $\mathrm{Mc}-3)$. BG$\mathrm{CPM}$ races $\mathrm{Mc}-2$ and $\mathrm{Mc}-4$ were each compatible on one line, THMC 170 and THMC 143, respectively, and Mc-3 was compatible on two lines, THMC 113 and THMC 170. We found two independent, recessive genes for resistance to race $\mathrm{Mc}-1$ in this study. Inheritance of resistance to the other three races remains to be determined; such studies will reveal new genes, perhaps some dominant, for resistance to these four races and give us a complete characterization of the of BG-CPM resistance gene combinations in these breeding lines. This information will inform efforts to combine $\mathrm{BG}-\mathrm{CPM}$ resistance genes in the next generation of $\mathrm{BG}$ breeding lines and cultivars that will potentially be more stable in terms of race durability. Knowledge of BG-CPM races is relatively new, and it remains to be determined whether $\mathrm{BG}-P x$ CPM interactions will be similar to the experience in melon, with many races, watermelon with two races, or be more like cucumber and squash which have not yielded new CPM races despite wide deployment of CPM resistance genes (Jahn et al., 2002).

For recessive resistance to be of use in $F_{1}$ hybrid cultivars, breeders must transfer the gene(s) to both parents. The alternate backcross and self-breeding procedure (Scully and Federer, 1993) should be effective in transferring recessive genes for resistance to commercially valuable cultivars. This approach has been adopted by the commercial BG breeders using these CPM resistance sources in their breeding programs (P. Agarwal, VNR Seeds Private Limited; R. Hegde, Noble Seeds Private Limited, personal communication).

Relying on a single source of resistance is not desirable based on the record of racespecific host parasite interactions (Van Der Plank, 1968), in particular on melon (Lebeda et al., 2016). To improve the durability of the resistance, it would be interesting to combine the resistance locus of THMC 143 with the locus of the four other resistant breeding lines. Molecular markers linked to the resistance alleles for marker-assisted selection would facilitate this effort. Collection of additional BG germplasm throughout the primary center of diversity (India, Bangladesh, Myanmar, and southern China) will supplant these unique sources of genes and loci for more durable resistance to BG-CPM, and help construct a narrative of the occurrence of the BG-CPM races across south and Southeast Asia.

\section{Literature Cited}

Ben-Naim, Y. and Y. Cohen. 2015. Inheritance of resistance to powdery mildew race $1 \mathrm{~W}$ in watermelon. Phytopathology 105:1446-1457.

Dhillon, N.P.S., A.J. Monforte, M. Pitrat, S. Pandey, P.K. Singh, K.R. Reitsma, J. Garcia-Mas, A. Sharma, and J.D. McCreight. 2012. Melon landraces of India: Contributions and importance. Plant Breed. Rev. 35:85-150.

Dhillon, N.P.S., S. Sanguansil, R. Schafleitner, Y.-W. Wang, and J.D. McCreight. 2016. Diversity among a wide Asian collection of bitter gourd landraces and their genetic relationships with commercial hybrid cultivars. J. Amer. Soc. Hort. Sci. 141:475-484.

Dhillon, N.P.S., S. Sanguansil, S. Srimat, B. Manjunath, P. Agarwal, Q. Xiang, M.A.T. Masud, T. Myint, H.T. Hanh, T.K. Cuong, C.H. Balatero, V. Salutan-Bautista, M. Pitrat,
A. Lebeda, and J.D. McCreight. 2018. Cucurbit powdery mildew-resistant bitter gourd breeding lines reveal four races of Podosphaera xanthii in Asia. HortScience 53:337-341.

Jahn, M., H.M. Munger, and J.D. McCreight. 2002. Breeding cucurbit crops for powdery mildew resistance, p. 239-248. In: R.R. Belanger W.R. Bushnell, A.J. Dik, and T.L.W. Carver (eds.) The powdery mildews: A comprehensive treatise. APS Press, St. Paul, MN.

Krístková, E., A. Lebeda, and B. Sedláková. 2009. Species spectra, distribution and host range of cucurbit powdery mildews in the Czech Republic, and in some other European and Middle Eastern countries. Phytoparasitica 37:337-350.

Lebeda, A., E. Kř́stková, B. Sedláková, J.D. McCreight, and M.D. Coffey. 2016. Cucurbit powdery mildews: Methodology for objective determination and denomination of races. Eur. J. Plant Pathol. 144:399-410.

Lebeda, A., M.T. McGrath, and B. Sedláková. 2010. Fungicide resistance in cucurbit powdery mildew fungi, p. 221-246. In: O. Carisse (ed.). Fungicides. InTech Publishers, Rijeka, Croatia.

McDonald, B.A. and C. Linde. 2002. Pathogen population genetics, evolutionary potential, and durable resistance. Annu. Rev. Phytopathol. 40:349-379.

McGrath, M.T. 2001. Fungicide resistance in cucurbit powdery mildew: Experiences and challenges. Plant Dis. 85:236-245.

McGrath, M.T. 2017. Powdery mildew, p. 62-64. In: A.P. Keinath, W.M. Wintermantel, and T.A Zitter (eds.). Compendium of cucurbit diseases and insect pests. 2nd ed. APS Press, St. Paul, $\mathrm{MN}$

McGrath, M.T., H. Stanisgewska, N. Shishkoff, and G. Casella. 1996. Fungicide sensitivity of Sphaerotheca fuliginea populations in the United States. Plant Dis. 80:697-703.

Scully, B.T. and W.T. Federer. 1993. Application of genetic theory in breeding for multiple virus resistance, p. 167-195. In: M.M. Kyle (ed.). Resistance to viral diseases of vegetables. Timber Press, Portland, OR.

Sitterly, W.R. 1978. Powdery mildews of cucurbits, p. 359-379. In: D.M. Spencer (ed.). The powdery mildews. Academic Press, New York. Van Der Plank, J.E. 1968. Disease resistance in plants. Academic Press, New York. 